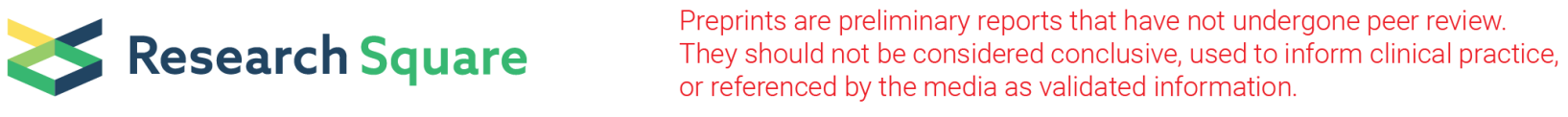

\title{
Professional Early-Adopter Experiences of Implementing a Novel Rehabilitation Model of Care across Alberta, Canada: A Focused Ethnography
}

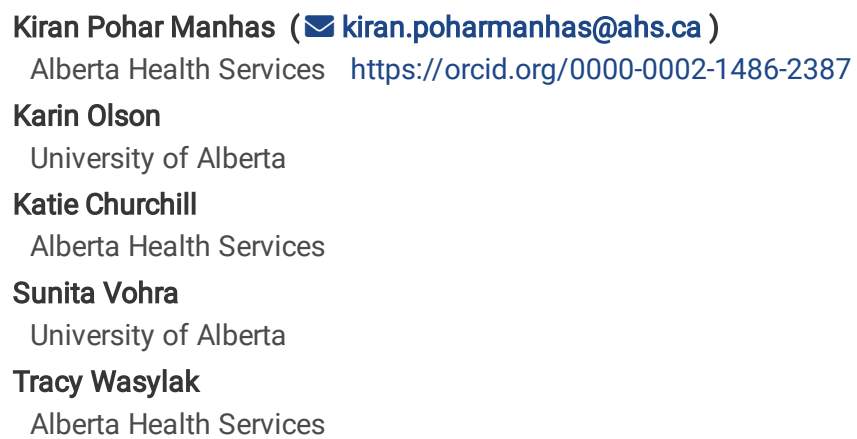

\section{Research article}

Keywords: model of care, barriers, facilitators, implementation, change management, provincial policy, professionals, early adopters, rehabilitation

Posted Date: September 12th, 2019

DOI: https://doi.org/10.21203/rs.2.14360/v1

License: (c) (i) This work is licensed under a Creative Commons Attribution 4.0 International License. Read Full License 


\section{Abstract}

Background In 2017, a provincial health-system released a Rehabilitation Model of Care (RMoC) to promote patient-centred care, provincial standardization, and data-driven innovation. Eighteen early-adopter community-rehabilitation teams implemented the RMoC using a 1.5-year long Innovation Learning Collaborative (in-person learning sessions; balanced scorecards). More research is required on developing, implementing and evaluating models of care. Understanding RMoC implementation will expand implementation science knowledge, particularly around factors influencing model-of-care outcomes and sustainability in, and between, jurisdictions. We aimed to explore experiences of early-adopter providers and provincial consultants involved in the community-rehabilitation RMoC implementation in Alberta, Canada.Methods Via focused ethnography, we used focus groups (or interviews for feasibility/confidentiality) and aggregate, site-level data analysis of RMoC standardized metrics. Purposive sampling ensured representation across geography, service types and patient populations. Team-specific focus groups were onsite, at participants' convenience, and led by a researcher-moderator and co-facilitator. A semi-structured question guide promoted discussions on interesting/challenging occurrences; perceptions of RMoC impact; and, suggested definitions of successful implementation. Focus groups and interviews were audio-recorded and transcribed alongside field notes. Data collection and analysis were concurrent to saturation. Transcripts were coded for implementation-related phrases. Similar ideas were collapsed forming themes, with inter-theme relationships identified. Tactics for rigour included negative case analysis, use of thick description, and an audit trail. Results We completed 11 focus groups and seven interviews (03/2018 to 01/2019) (n=45). Participants were $89.6 \%$ female, mostly-Canadian trained and represented diverse rehabilitation professions. Teams varied on their focal health service and patient population. The implementation experience involved navigating emotions, operating amongst dynamics, and integrating the RMoC details. Confident, satisfied early-adopter teams demonstrated traits including strong coping strategies; management support; and, being opportunistic and candid about failure. Teams faced common challenges (e.g. emotions of change; delayed data access; and lack of efficient, memorable communication across team and site). Implementation success targeted patient-, team- and system levels.Conclusions We recommend specific training priorities for future teams including evaluation training for novice teams; timelines for step-wise implementation; on-site, in-person time with a facilitator and full-team present; and prolonged facilitated introductions between similar teams for long-term mentorship.

\section{Background}

\section{Contributions to the Literature}

- We studied diverse early-adopter experiences in the implementation of a new Rehabilitation Model of Care in community rehabilitation across a large provincial health system.

- Cross-jurisdictional factors critical to Model spread were informed by studying diverse demographic profiles varying by geographical area (including rural and regional), patient population (e.g. musculoskeletal vs. neurological rehabilitation), and service programming (e.g. group vs. individual programming).

- As models of care continue to emerge as policy innovations to promote equity and patient-centredness across systems, this study contributes clarity on common challenges, facets of success, and strategies to support model spread and scale.

In our provincial health-system, rehabilitation aims for "enhancing function for meaningful living" [1]. In April 2017, a redesigned Rehabilitation Model of Care (RMoC) was introduced provincially to cultivate a patient-focused, innovative, equitable and data-driven service model provincially [1-4][5, 6]. This coincides with the refrain "no decision about me without me" $[7,8]$ that undergirds many global, national and provincial movements to better empower patients in their health, healthcare, and research [8-12].

\section{Models of Care and Their Implementation}

Understanding the implementation of policy innovations, like the RMoC, is critical to understanding change within complex health systems. Such understanding will build new knowledge in implementation science, particularly on why models of care work in a particular jurisdiction and factors that influence model outcomes between jurisdictions $[13,14]$. There is a call for more research on developing, implementing and evaluating models of care [15]. Model-of-care evaluation must consider practices and outcomes before and after a model is introduced.

A model of care is an "... evidence-informed policy or framework that outlines the optimal manner in which condition-specific care should be made available and delivered to consumers at a system level" [15]. It is not a clinical guideline, but a vehicle for moving best evidence into practice using appropriate teams, timing and resources $[15,16]$. In Australia, Canada, the US and the UK, models of care are increasingly developed for diverse settings including chronic conditions [17, 18], e-health strategies [19, 20], mental health [20,21], musculoskeletal issues [15, 22, 23], pregnancy [24], and primary and community care [25].

Research on perceived barriers and facilitators to implementing new models of care found that sustainable change is challenging [22-26]. These facilitators included organizational cultures and stability; champions for change; individual acceptance; supportive leadership; distribution of decisionmaking roles; and systematic follow-up and measurement [21, 24, 25, 27]. Recognized barriers included communication barriers; intra-organizational competition (e.g. lack of formalized collaboration); organizational structures; lack of buy-in; limited financial resources; overwhelmed or unsupported staff $[18,20,21,24,27]$. This research spans clinical settings including musculoskeletal conditions, but does not address factors unique to community rehabilitation (e.g. predominantly allied-health providers, outpatient settings) [15, 17-25]. 
Implementation science theory supports understandings around why models of care work in a particular jurisdiction and clarify factors to consider when transferring the model between jurisdictions [13, 14]. The Consolidated Framework for Implementation Research (CFIR) represents a framework and "over-arching typology" to understand implementation developed from combining common constructs from published theories [14, 28]. CFIR aims to promote theory development and verification around "... what works where and why across multiple contexts" [28]. Implementation is viewed as "... the transition period during which targeted stakeholders become increasingly skillful, consistent, and committed in their use of an intervention" [28].

The CFIR describes five domains, with a total of 37 constructs across the domains, that influence implementation effectiveness in multiple, complex ways individually, interactionally and collectively [29]. The five domains relate to characteristics of the intervention (e.g. 'core components' vs. 'adaptable periphery' of the intervention; the intervention's complexity, costs, course, and evidential base); the outer setting (e.g. network with external organizations, peer pressure, patient needs and resources, and external policies or incentives); the inner setting (e.g. internal structural characteristics, communication, climate, and culture); characteristics of individuals (e.g. self-efficacy, knowledge/attitudes/beliefs, personal attributes; individual state of change); and the implementation process (e.g. the activities of planning, engaging, executing, and reflecting and evaluating) [29]. This framework supports strategic assessments of potential barriers and facilitators to the implementation of a novel innovation, including a model of care [13].

\section{Organizational Context}

The RMoC has five competency domains: access and wayfinding; service options, client and community outcomes, transitions, and professional practice (Figure 1) [4]. The RMoC mandates standardized tools to capture collaborative goal-setting and patient-reported outcomes, including quality of life (EQ-5D-5L) and care experience (WatLX ${ }^{\mathrm{TM}}$ ) $[30,31]$. These metrics map onto recognized quality dimensions of effectiveness $(\%$ clients reporting clinical improvement in EQ-5D-5L), acceptability (\% clients reporting a positive experience on WatLX ${ }^{\mathrm{TM}}$ ) and appropriateness (\% clients setting a collaborative, functional goal) [32]. This will inform implementation, policy development, quality improvement, accountability, comparisons and research.

RMoC adoption began May 2017: 18 community rehabilitation teams volunteered as Early Adopters. Early Adopters then implemented the RMoC while being stewarded through the 1.5-year Innovation Learning Collaborative change-management process. Based on the Institute for Healthcare Improvement's Collaborative Model for Achieving Breakthrough Improvement, the Innovation Learning Collaboratives gave structure and process that engaged local teams to make changes towards health system advancement [33-38]. The Innovation-Learning-Collaborative process involved several learning strategies including independent study, team-based learning, face-to-face learning sessions, and team-driven balanced scorecards for progress measurement [33].

Separate from the RMoC, the provincial health system broadly introduced HealthChange ${ }^{\circledR}$ Methodology [39]. HealthChange ${ }^{\circledR}$ focuses on educating providers to help patients make behavior changes for health promotion [40]. HealthChange ${ }^{\circledR}$ training discusses person-centred approaches to patient engagement that may influence shared decision-making or collaborative goal-setting [40]. The 18 Early-Adopter teams implementing the RMoC had priority to participate in the training.

\section{Gaps in Understanding}

There has been no formal evaluation of the Innovation-Learning-Collaborative process or the RMoC in the Early-Adopter teams. The literature around the development, implementation and evaluation of models of care is quite nascent, particularly in community rehabilitation. We aimed to contribute clarity on the implementation of novel models of care, which in this context would also support the provincial spread and scale of the RMoC. This study is part of a broader research program examining the implementation and impact of the RMoC; this manuscripts focuses' on provider experiences of implementation, while other under-review manuscripts describe patient and provider perspectives on shared decision-making both pre-,[41], and post-, [42], RMoC.

\section{Methods}

In this study, we aimed to explore the experience of implementing the RMoC. We asked: how do providers and professionals involved in the early adoption of the RMoC in Alberta describe the experience of implementation?

We used focused ethnography in this research program [43]. Ethnography involves making cultural inferences from peoples' communications, actions and artifacts [44]. The culture of interest included patients and professionals composing diverse community rehabilitation sites across Alberta. Focused ethnography uniquely focuses on specific problems and contexts; on discrete social phenomena; on a single researcher's conceptual orientation; on small samples; on limited to no participant observation; and on academic and healthcare settings $[45,46]$.

\section{Study Population \& Recruitment}

Study sites or teams included those involved in enacting, directing, or supporting the early adoption of the new RMoC between April 2017 and June 2018. Purposive sampling ensured site sampling across geographically- and patient-population-wise- diverse settings provincially, including rural (<10000 population), regional-urban (population between 10000 and 100000); and metropolitan-urban (>100000 population) geographical settings, while accommodating feasibility and managerial considerations. 
Inclusion criteria for participants whether providers, leadership or consultants, was either recognized membership on an Early-Adopter community rehabilitation team or a professional role facilitating RMoC implementation. Rehabilitation providers must have held a professional license, as appropriate, during implementation. No exclusion criteria were set.

Site leadership informed provider recruitment strategies. Tactics included email introductions followed by study presentations (by webinar, in-person, or one-on-one) overviewing aims, methods and implications. After discussions with the previously-unknown researcher, informed consent was procured.

\section{Data Collection}

We used focus group methodology $[47,48]$. Each focus group was limited to members of that team. Participants were offered the alternative of individual interview participation if preferred for confidentiality or scheduling. We also examined aggregate standardized-metric data (i.e. EQ-5D-5L and WatLX ${ }^{\mathrm{TM}}$ ) collected by Early Adopter team during the Innovation-Learning-Collaborative period (July 2017 to November 2018 ), and located on the provincial health-system's cloud-based data-visualization program.

Site managers worked with staff to organize focus group timing and location. In-person focus groups (or interviews) were in private rooms at rehabilitation sites. The provincial-consultant focus group used video discussions due to geography. The research team traveled to teams. Prior to the focus group, all participants received the written consent form, focus group guidelines and outline document, study backgrounder, and a confidentiality agreement. The experienced, PhD-trained lead researcher (KPM) moderated all focus groups to facilitate discussion; a second research personnel assisted her as co-facilitator to log non-verbal behaviours and group dynamics in field notes [48]. Due to geography and cost, the co-facilitator varied and included either a hired clerical staff, therapy assistant, patient-researcher, or research trainee.

Focus groups were guided by a semi-structured question guide. Discussion centred on participants' (a) experience of RMoC implementation; (b) experiences that they found interesting or challenging during implementation; (c) perceptions of the RMoC in practice; and, (d) criteria for defining successful RMoC adoption.

Prior to data collection, previous Phase 1 provider-participants gave feedback on the question guide. The moderator convened the focus group, beginning with an ice-breaker and introduction. The moderator used verbal and non-verbal approaches (e.g. calling on quieter participants, using head nodding and eye contact) to encourage participation [48]. All focus groups and interviews were audio-recorded and confidentially transcribed. Interviews followed same question guide.

The moderator and co-facilitator debriefed after each session to ensure complete field notes; co-facilitators shared detailed field notes and their impressions of key-takeaways from the conversation.

Both the process of collection and the outcomes in the three standardized-metrics provided important insight into the issues related to success and sustainability of RMoC adoption for each team. Primary data collection was a new experience for teams. We gained secondary access to the aggregate data on the provincial health-system's data-visualization platform specifically on the three standardized metrics (EQ-5D-5L, WatLX ${ }^{\mathrm{TM}}$, and Collaborative Goal Setting) for the period of the Early-Adopters' Innovation-Learning-Collaborative (April 2017 and November 2018).

\section{Data Analysis}

Data collection and analysis of field notes, transcripts, and any participant notes, was concurrent [43, 44]. Analysis began by uploading cleaned transcripts into NVivo, with coding of transcripts for words and phrases related to implementation, including experiences, successes and challenges. Recruitment, data collection, and data analysis continued until no new information about the dimensions of implementation were obtained. The research-trainee co-facilitator examined three coded transcripts to ensure appropriateness and no missing codes. Similar ideas were grouped together to form themes, with tentative relationships among the themes identified. This qualitatively-derived description of the implementation experience of EarlyAdopter teams and leadership was contextualized by descriptive analyses of site-level data including standardized RMoC metrics. An audit trail of decisions was kept to ensure rigour [49].

Data analysis also considered the unique attributes of focus group research, particularly participant interaction [50-52]. Coding was informed by the nuances of focus group interactions, including an examination of the sequence of responses to determine the process of evolving consensus and debate; an appreciation of individual contributions along the group discussion; and, an exploration of the impact made by types of questions (e.g. general vs. specific; particular topics) [52]. Any perceptions of consensus amongst a group was tempered by recognition of the influence of group dynamics, discussion and conformity [50]. We examined group adherence to issues posed by the moderator; sequence of discussion; context of group debate or conflict; presence of alliances among group members; resolution of disagreements; interests represented amongst group; emotionality of discussion or members; and, common experiences expressed [50].

We used the provincial health-system's data visualization platform to analyze Early-Adopters' aggregate data, and SPSS 25 for the provider sociodemographic data collected in focus groups. For each site, we analyzed the quantitative data to consider the collection process and outcomes related to the standardized metrics: EQ-5D-5L, WatLX $X^{T M}$, and collaborative-goal-setting and site characteristics (e.g. disciplines, number of patients per month). We statistically described these data using means, standard deviations and ranges for continuous variables (e.g. number of patients) and proportions for categorical data (e.g. types of disciplines). Process-wise, we determined how many months after the April-2017 start of the Innovation- 
Learning-Collaborative process did the team begin data collection generally, and for each of the three standardized metrics specifically. We used a monthly time series plot for the number of metrics captured for each standardized metric over the April 2017 to November 2018 period (3 variables on one plot, each with a different line). The consolidated criteria for reporting qualitative research (COREQ) was used; checklist available in Additional File 1.

\section{Results}

\section{Participant Information}

Ten of the 18 Early Adopter teams took part, as well as a provincial team of community rehabilitation senior practice consultants. In total, 47 professionals participated in focus groups or interviews (30-to-120-minutes duration). The researchers conducted 11 team-specific focus groups ( $\mathrm{n}=2-7$ participants per group) and seven one-on-one interviews. Save the provincial consultant-team, all focus groups were in-person at locations specified by the team. Interviews were by phone (2) or in-person (5). Saturation was achieved.

Five teams represented metropolitan-urban settings, one team represented regional-urban settings, and four represented rural settings. While the Innovation-Learning-Collaborative process began in May 2017, teams varied on when they initiated the novel, RMoC-required data collection processes. For the available data from eight teams, three teams began collecting the standardized metrics data in July 2017, two in August 2017, one in September 2017, one in October 2017 and one in November 2017. The data collection start time was not associated with geographic setting or survey delivery format (i.e. paper vs. iPad vs. both). We found that mean completion rates were $87.25 \%$ at sites using paper-copies only, and $95 \%$ at sites using both iPad and paper copies together.

We examined the WatLX ${ }^{\mathrm{TM}}$ completion rates and actual measures at the available eight sites. Across July 2017 to November 2018 , on average $85 \%$ of patients responded entirely agree or mostly agree on the ten individual WatLX ${ }^{\mathrm{TM}}$ items. Individual items that had a higher response rate for not applicable related to inclusion of chosen family and friends (32\%), control of physical pain (15\%), and no delay on information availability (13\%).

We examined the EQ-5D-5L completion rates and actual measures at nine available sites between July 2017 and November 2018 . Sites collected 1376 intake EQ-5D-5L surveys and 753 end-of-episode-of-care EQ-5D-5L surveys. In July 2017, the ratio of intake EQ-5D-5L surveys completed to end-of-care EQ-5D-5L surveys was $86.61 \%$ to $13.39 \%$. In November 2018 , this ratio was $64.36 \%$ intake and $36.54 \%$ end-of-care surveys. Across the nine sites, the mean change in EQ-5D-5L Index Score was 0.11 in July 2017 and 0.09 in November 2018. The largest monthly mean change in EQ-5D-5L Index Score was 0.14 and the lowest monthly mean change was 0.04 : these are all above the minimally-important difference of 0.037.[53] The mean number of patients who indicated that they had no problem across the five EQ-5D-5L dimensions was $31.80 \%$ at intake, and $41.27 \%$ at the end of care.

\section{Professionals' Experience of RMoC Implementation}

The experience of implementing the RMoC called upon teams to navigate emotions, operate amongst myriad dynamics, and integrate novel RMoC processes (Figure 2). Professionals described implementation success as multi-faceted, relating to patient metrics, team processes, and system efficiency (Figure 3). The frameworks reveal the traits of confident, satisfied teams, and challenges common to most RMoC-implementation experiences.

\section{Navigate Emotions}

The emotional fall-out of RMoC implementation was prominent to Early Adopter professionals. Emotions and connections were intertwined for providers. Many providers spoke of developing a common, shared language during implementation, which was facilitated through training (e.g. HealthChange ${ }^{\circledR}$ ) and transdisciplinary approaches. All teams experienced feelings of frustration, anxiety and being overwhelmed, especially at the start of implementation. Failure, or when things did not go as planned, often causes stress, challenges and other negative emotions at the individual- and team- level. Teams varied in their approach to failure. Some teams were open and candid about failure and took an opportunistic "fail fast, fail forward" approach. This mitigated stress and negativity, and it pre-empted failure-related delays. Other teams were more hesitant to change their plans when things did not go as expected. Exemplar quotes from professionals substantiate the emotional navigation in RMoC implementation (Table 1). In-text, we provide one quote for the three key aspects of navigating emotions: shared language, feelings and approach to failure, respectively.

"[HealthChange] gave us the language I think right. We were able to have easier conversations around our clients because HealthChange gave us the lingo, the terminology so that we were all on the same page." [Focus Group 4 Participant]

"So that first session was very frustrating admittedly. It was very confusing. It was hard to understand what the ultimate goal was and what we were expected to achieve at the session. So when we got to the end of the session and ... they're looking to me essentially to make some decisions as to what we're doing, and I'm like 'I still really don't understand the question."' [Focus Group 8 Participant]

"One thing for the teams that are starting out being able to continue to look at it and re-evaluate things and not being afraid of changing and failure trying things out and just keep just keep trying." [Focus Group 10 Participant] 
Table 1. Professional Quotes on Navigating Emotions in the RMoC Implementation Experience

Navigating Emotions

\begin{tabular}{|c|c|}
\hline $\begin{array}{l}\text { Shared } \\
\text { Language }\end{array}$ & $\begin{array}{l}\text { Finding common language } \\
\text { "P1: Made a more conscious effort of looking at how we were providing our services and just being more effective and more client-centred. } \\
\text { P2: It just brought a different language to it." [Focus Group } 4 \text { Participant] } \\
\text { Training } \\
\text { "[HealthChange] gave us the language I think right. We were able to have easier conversations around our clients because HealthChange gave us the lingo, } \\
\text { the terminology so that we were all on the same page." [Focus Group } 4 \text { Participant] } \\
\text { Transdisciplinary } \\
\text { "And that's the thing right, you definitely have to leave your territory. Like walk out of your territory into neutral territory, and then just accept it from } \\
\text { there." [Focus Group } 9 \text { Participant] }\end{array}$ \\
\hline Feelings & $\begin{array}{l}\text { Frustration } \\
\text { "So that first session was very frustrating admittedly. It was very confusing. It was hard to understand what the ultimate goal was and what we were } \\
\text { expected to achieve at the session. So when we got to the end of the session and ... they're looking to me essentially to make some decisions as to what we're } \\
\text { doing, and I'm like 'I still really don't understand the question.'” [Focus Group } 8 \text { Participant] } \\
\text { Anxiety } \\
\text { "P5: It's a huge change. So, the level of anxiety on everyone is quite high, including myself. And January was probably a pinnacle of whatever can happen, } \\
\text { can happen: from clients not knowing where to go, to computer failure... } \\
\text { P1: We lost our admin staff. } \\
\text { P5:... So there was a lot of flipping around which can cause so much anxiety and a lot of confusion." [Focus Group } 3 \text { Participants] } \\
\text { Overwhelmed/confused } \\
\text { "I think it was just kind of mind-blowing at first. We didn't really realize what it was and we went there [to the Learning Session] and it was like 'wow this is } \\
\text { what we're doing and how do we put this all together.' So, it was a lot of information all at once, but inspiring to be able to take that back and to work on it } \\
\text { within our small team." [Interview } 2 \text { Participant] }\end{array}$ \\
\hline $\begin{array}{l}\text { Approach } \\
\text { to } \\
\text { Failures }\end{array}$ & $\begin{array}{l}\text { When candid } \\
\text { "One thing for the teams that are starting out being able to continue to look at it and re-evaluate things and not being afraid of changing and failure trying } \\
\text { things out and just keep just keep trying." [Focus Group } 10 \text { Participant] } \\
\text { Fail fast, fail forward } \\
\text { "P5: Yeah and I think that like from a lead perspective, we wanted to make a change, but we didn't hesitate to review and say 'well that didn't work, lets do } \\
\text { something else.' And not be stuck on something. } \\
\text { P1: As [the Special Practice Consultant] says, fail fast, fail forward, we did that really well, we really did." [Focus Group } 3 \text { Participant] } \\
\text { Fear of changing plan } \\
\text { "Another team, they really felt like they had to do one of the service options, which is a component of the Model of Care. And they just got it in their head } \\
\text { and it didn't seem to matter how I tried to maneuver around [that] 'you have other options we can explore, other things here', they just had it in their head. } \\
\text { And I never was able to really move them from that initial thing that they thought they had to do. They had a lot of learnings, but I think their experience } \\
\text { could have been different if I'd been able to move that stereotype that they held onto for so long." [Focus Group } 11 \text { Participant] }\end{array}$ \\
\hline
\end{tabular}

\section{Operating amongst Dynamics}

Early-Adopter teams faced challenges and made adaptions for micro-, meso- and macro- level dynamics. At the micro-level, patient-provider interactions were routed towards emphasis on patient readiness and understanding for fully-informed participation. This was especially prominent during screening and intake. At the meso-level, interactions amongst team members influenced implementation. Management support determined the relative ease of implementation. Change in team membership was a common challenge, which some teams handled well while others did not. At the macro-level, the use and availability of organizational resources was noted and critical to professionals. Perceived inefficiencies in resource use, particularly around the four in-person Learning Sessions (as part of the Innovation-Learning-Collaborative), concerned professionals, as did any unavailability or inconsistency in necessary resources. Resources included time, physical and human resources. Table 2 provides transcript quotes demonstrating these dynamics. Intext, we provide one quote for the three key aspects of these dynamics: the patients, the team, and the resources, respectively.

"It's really focused more in the last little while. We revamped it since attending the HealthChange methodology group session. We changed the focus to be a lot more focused on readiness. Having the client be aware of what the treatment might involve, what the options are with treatment. So they just come a little bit more informed to make an informed decision." [Focus Group 4 Participant]

"Yeah, lots of mat leaves and coverages and people leaving early and so we were in scramble mode for the last year just trying to get through our day in peace." [Focus Group 4 Participant]

"P1: We've always struggled with that and people have great ideas about how to help us with our problems. But that's because they have all these resources and funding for all this...

P2: I think like the community support right. A lot of those programs are run off site at gyms and there's collaborative partnerships, which we don't have." [Focus Group 1 Participants]

Table 2. Professional Quotes on Operating Amongst Dynamics in the RMoC Implementation Experience 


\begin{tabular}{|c|c|}
\hline $\begin{array}{l}\text { The } \\
\text { Patients }\end{array}$ & $\begin{array}{l}\text { Readiness } \\
\text { "It's really focused more in the last little while. We revamped it since attending the HealthChange methodology group session. We changed the focus to be a } \\
\text { lot more focused on readiness. Having the client be aware of what the treatment might involve, what the options are with treatment. So they just come a } \\
\text { little bit more informed to make an informed decision." [Focus Group } 4 \text { Participant] } \\
\text { Screening and intake } \\
\text { "The process of getting to [this program] is actually quite a long journey. Longer than the actual program itself. So we tried to set up a metric to see if we } \\
\text { could reduce that, and try to evaluate that. The end result is that we have in some sort established a more streamline approach to assessing a client so that } \\
\text { they have an idea of whether they're able to make it into class or if their accepted to class or not be accepted to class. And then help them way-find if } \\
\text { they're not." [Focus Group } 3 \text { Participant] } \\
\text { Consent } \\
\text { "We want them to be informed and to be ready for the coming to treatment because it's a really large commitment that we're asking them to do so we want } \\
\text { them to feel like that they're a part of what we're offering and that they know what they're getting into." [Focus Group } 4 \text { Participant] }\end{array}$ \\
\hline & $\begin{array}{l}\text { Management } \\
\text { "The challenges that I can think of were around the trans-disciplinary model and the challenges around having constant FTE available. So we struggled with } \\
\text { [discipline A] and [discipline B] for a number of months because management was saying they were supportive of it, but yet maybe not so ... when you're } \\
\text { withdrawing [these disciplines] for periods of day [sic] it really affects the structure and the process that we were trying to build." [Focus Group } 10 \\
\text { Participant] } \\
\text { Team changes } \\
\text { "Yeah, lots of mat leaves and coverages and people leaving early and so we were in scramble mode for the last year just trying to get through our day in } \\
\text { peace." [Focus Group } 4 \text { Participant] } \\
\text { Other colleagues } \\
\text { "It [was] really, really difficult to come back from the session and explain it to anybody because really I found it very difficult.... The model is very large and } \\
\text { the amount of stuff that we could put into place is huge. And understanding how much of that we were expected to be incorporating into our site that wasn't there are so many different aspects and so are we supposed to be doing all of them, are we only supposed to be doing a little bit of it, do we } \\
\text { only apply it to the [specific program] group?" [Focus Group } 8 \text { Participant] }\end{array}$ \\
\hline $\begin{array}{l}\text { The } \\
\text { Resou }\end{array}$ & $\begin{array}{l}\text { Perceived efficiency } \\
\text { "Moderator: How did you compare the Telehealth Learning Session to the in-person ones? } \\
\text { P1: Much better use of time and money } \\
\text { P2: And it was nice we were all there for that one } \\
\text { P3: Yeah everybody was in the same room, so then we could all have the same discussion afterwards } \\
\text { P2: And hear the same thing." [Focus Group } 9 \text { Participants] } \\
\text { Learning Sessions } \\
\text { "[At the Learning Session], I personally think with doing it on our own time, how it would have probably worked better on a smaller scale is to have goals. ... } \\
\text { It was really too much fluff, too much things. But if you had set it up and said okay I, we're starting in April so by May/June we need you to have this metric } \\
\text { done. You're like okay and if you need this metric done in June, you have a timeline that you work back to April. ... If it was broken down a bit more like that, } \\
\text { practical like that, I think it would have been better." [Focus Group } 2 \text { Participant] } \\
\text { Available Resources } \\
\text { "P1: We've always struggled with that and people have great ideas about how to help us with our problems. But that's because they have all these resources } \\
\text { and funding for all this... } \\
\text { P2: I think like the community support right. A lot of those programs are run off site at gyms and there's collaborative partnerships, which we don't have." }\end{array}$ \\
\hline
\end{tabular}

\section{Integrating the Model}

The implementation experience hinged on three aspects related to the integration of RMoC polices and processes. First, some teams questioned the introduction of data collection using RMoC standardized and non-standardized metrics. It was difficult to see the value in the data. Some metrics were problematic due to ceiling effects or inapplicability to unique populations. Prolonged delays in access limited data utility.

Second, RMoC implementation was accompanied by either novel service programming or an opportunity to highlight provincially-unique, long-standing site services. Some teams then inappropriately conflated the RMoC and service programming. Some teams struggled to understand the rationale and aspects of the RMoC despite implementation activities. These struggles and misunderstandings often led to lower prioritization of the RMoC, and thus limited its full integration.

Third, RMoC integration tied to information availability. Some team members avoided extraneous information in their daily tasks, which sometimes included RMoC-related information. Team leads in the ILC process consistently had the greatest connection and understanding of the RMoC, which was accompanied by disparities in understanding across the rest of the team. Training and learning opportunities were most memorable and impactful when in-person, practice-relevant and resource-efficient. In-person interactions that were perceived as inefficient or irrelevant were both unmemorable for content, and associated with negative attributes. Table 3 contains quotes supporting these features. In-text, we provide one quote for the three key aspects of these dynamics: the metrics, model vs. program, and available information, respectively.

"I think the issue with some of the mandatory indicators is there's not a lot of play in it. So if you're already scoring a nine or a ten from day one, where is the challenge? And that's what I see as a scorecard is like as team can we then use that to challenge ourselves, push ourselves even further into clientcentred-ness? But we're stuck to those and I don't want to add in another outcome measure right onto our clients' back." [Focus Group 10 Participant] 
"The model of care was not first and foremost in my mind, ever. I'm sorry to say, I know you worked very hard at developing this. But basically when you're on a floor working with clients, you're trying to get your day to day done. Clients need to be seen. They need to be heard. Sometimes I think I have a second mom role. ... I'm working. People are talking to me. They're saying all sorts of things." [Focus Group 2 Participant]

"It seems like we retained the in person stuff a lot better. ... The practical side of it. We could practice. It was much more useful, much more effective so." [Focus Group 3 Participant]

Table 3. Professional Quotes on Integrating the Model during RMoC Implementation Experience Integrating the Model

\begin{tabular}{|c|c|}
\hline $\begin{array}{l}\text { The } \\
\text { Metrics }\end{array}$ & $\begin{array}{l}\text { Difficult to see value } \\
\text { "I found it hard to understand how the outcome measures of the measurement tools that we needed to use applied to the Model of Care. ... [I was] excited } \\
\text { that we were kind of there and what more we were going to learn, but didn't quite get the connection of how the two roles blended with the Model of } \\
\text { Care." [Focus Group } 7 \text { Participant] } \\
\text { Some metrics problematic } \\
\text { "I think the issue with some of the mandatory indicators is there's not a lot of play in it. So if you're already scoring a nine or a ten from day one, where is } \\
\text { the challenge? And that's what I see as a scorecard is like as team can we then use that to challenge ourselves, push ourselves even further into client- } \\
\text { centred-ness? But we're stuck to those and I don't want to add in another outcome measure right onto our clients' back." [Focus Group } 10 \text { Participant] } \\
\text { Access to data } \\
\text { "There was just a lot of trouble getting information back about it, so it was really hard for staff and unit perspective because we'd have loved to have given } \\
\text { it back to staff. But it took probably like eight nine ten months to get any bulk number back in order to support staff by giving them that feedback and so } \\
\text { that was really rough." [Focus Group } 5 \text { Participant] }\end{array}$ \\
\hline & $\begin{array}{l}\text { Novelty } \\
\text { "If they didn't have a strong understanding of the Model it kind of came out as well in those expressions of interest because they weren't necessarily linked } \\
\text { really strongly with the Model. But we were also learning what the Model was as well. ... So I felt quite a long time for me to get from starting the position } \\
\text { and the teams coming on to really feeling I'm fairly solid in what the Model meant, so that was challenging. " [Focus Group } 11 \text { Participant] } \\
\text { One or other } \\
\text { "I still to this day we haven't had any formal orientation or information on the rehab Model of Care. All of a sudden this new one was shared with us by the } \\
\text { way it flashed up on the screen at the last learning session this is what we're doing now and I remember asking okay so can you provide us with documents } \\
\text { like you did for the original community rehab model of care so we can understand what's different. ... Don't tell us to roll something out if you're not } \\
\text { providing us with the information. You may theoretically understand it but how does it work at a practical level?"[Focus Group } 7 \text { Participant] } \\
\text { Priority } \\
\text { "The model of care was not first and foremost in my mind, ever. I'm sorry to say, I know you worked very hard at developing this. But basically when you're } \\
\text { on a floor working with clients, you're trying to get your day to day done. Clients need to be seen. They need to be heard. Sometimes I think I have a } \\
\text { second mom role. ... I'm working. People are talking to me. They're saying all sorts of things." [Focus Group } 2 \text { Participant] }\end{array}$ \\
\hline $\begin{array}{l}\text { Available } \\
\text { Information }\end{array}$ & $\begin{array}{l}\text { Avoid extraneous info } \\
\text { "We do not clutter our minds with things that do not concern us." [Focus Group } 9 \text { Participant] } \\
\text { Team lead access } \\
\text { "It feels like there's been certain players that have contributed to ILC. So certain members of the team. But it hasn't been dispersed amongst all members } \\
\text { of the team, so I know certain people we will attend meetings and that kind of thing but doesn't necessarily involve the whole team." [Focus Group } 4 \\
\text { Participant] } \\
\text { In-person memorable } \\
\text { "It seems like we retained the in person stuff a lot better. ... The practical side of it. We could practice. It was much more useful, much more effective so." } \\
\text { [Focus Group } 3 \text { Participant] }\end{array}$ \\
\hline
\end{tabular}

\section{$\underline{\text { RMoC Implementation towards Multi-faceted Success }}$}

Professional participants described successful implementation as multi-faceted, not monolithic. Success fell across micro-, meso- and macro- levels. Success was measured in improvements in patient experience and outcomes, as measured by the standardized RMoC metrics. Team processes tracked success, particularly whether the team was cohesive, collaborative and resilient through the inevitable challenges of implementation. RMoC success was tied to whether implementation introduced efficiencies for the health system.

"I think the way we measure success, and know we've done a good job, is looking at our patient satisfaction and our patient feedback. And did the clients actually get what they needed out of [the site]." [Focus Group 4 Participant]

"I don't think metrics is the only way to measure success. ... I think there also needs to be discussion about how we felt about the successes we had. To take on all of those changes and come out like a year later. ... Do you remember January of 2018?" [Focus Group 4 Participant]

"I think success is not just getting to a spot and being happy with it. It's constantly re-looking at things and making those changes to make it even better and better all the time. And I think that's kind of where my thoughts really changed with this kind of collaborative is how can I make each little piece even more successful, even better, each time. How can I reach a higher standard?" [Interview 2 Participant]

\section{Discussion}


Understanding the professional-participants' experience as Early Adopters of the RMoC clarifies commonalities. First, the features and framework of the implementation experience house a list of common challenges (Figure 4). Clarity on those challenges can help prepare future teams, and the leadership supporting them, on what to expect during RMoC implementation. Challenges directly impacted motivation and capacities to implement the RMoC, so overcoming these with concrete actions can support faster and smoother RMoC spread.

These challenges included: (a) difficulty in handling and navigating the initial emotions of large-scale change, which stressed team members and affected motivation; (b) lack of timely data access; (c) misunderstanding the relevance of RMoC metrics; (d) lack of efficient, memorable updating and training strategies for teams; (e) lack of clarity on the RMoC aim, vision and key components; (f) lack of sufficient time and coverage for clinical responsibilities to complete implementation tasks; and (g) perceptions of uniqueness impeding collaborative and mentorship opportunities.

Some Early Adopter teams had a fraught and challenging experience of RMoC implementation. Other teams described an experience marked with confidence, satisfaction and associations with the various levels of success. These confident teams had four features in common (Figure 5). They had coping strategies that pre-empted delays upon management or team-member changes (e.g. strong communication, human resources to supplant gaps as new members came up to speed). They used the RMoC and HealthChange® strategies to build a common language that facilitated communication amongst the team, with external colleagues, and with patients. They consistently addressed failure with candor and opportunism. Finally, they felt tangible management support for implementation tasks, and less top-down decision-making.

We developed recommendations for RMoC spread (Table 4). These recommendations highlight educational priorities for staff (e.g. evaluation training); areas to emphasize more frequently (e.g. the RMoC aim); inevitable experiences to prepare for (e.g. supporting the natural feelings of being overwhelmed and anxiety related to changing processes); examples and strategies to share (e.g. a timeline to adopt the RMoC in sequential parts); and the optimal format for educational endeavors (e.g. efficient, in-person sessions with the full team present when decisions are required to plan implementation). These recommendations target leadership, consultants and future teams.

Table 4. Recommendations in the Future Implementation of the RMoC 


\begin{tabular}{|c|c|}
\hline \multicolumn{2}{|r|}{ Recommendations to Leadership, Consultants, and Future Teams in Spreading the RMoC } \\
\hline \multicolumn{2}{|r|}{ Navigating Emotions } \\
\hline Feelings & $\begin{array}{l}\text { Prepare teams for likely initial feelings of confusion, frustration and being overwhelmed. This was not unusual for previous teams, and they do pass. } \\
\text { Perhaps with subsequent implementations, an Early Adopter team could come and speak to providers about what to expect. } \\
\text { Break down the RMoC and its implementation into step-by-step parts with an accompanying timeline. Provide it to teams early in the process. } \\
\text { Regularly reinforce that patience is often needed for large-scale change and that evidence of impact may not be readily or immediately visible. There } \\
\text { should be an emphasis on the import of measurement in large change showing small and early gains. }\end{array}$ \\
\hline $\begin{array}{l}\text { Shared } \\
\text { Language }\end{array}$ & $\begin{array}{l}\left.\text { Inform teams that a recognized value of the RMoC and related training (e.g. HealthChange }{ }^{\circledR}\right) \text { is a shared language amongst teams and patients. } \\
\text { Multidisciplinary teams must be steadfast in their planning, approach and criteria to garner the shared language needed to become transdisciplinary. } \\
\text { Management and provincial consultants could directly empower teams to deal with resistance to change (from within and outside the team) using group } \\
\text { discussions and shared resources on conflict negotiation and on the RMoC's vision and aims. }\end{array}$ \\
\hline $\begin{array}{l}\text { Approach } \\
\text { to Failures }\end{array}$ & $\begin{array}{l}\text { Facilitate transparent, constructive discussions on approaches to failure, and the benefit of viewing failure with a candid and opportunistic mind-set. } \\
\text { Incorporate the mantra "Failing fast, and failing forward" into RMoC implementation discussions so that failure is not viewed as a flaw to hide. } \\
\text { Clarify where there is flexibility in RMoC adoption, so teams can customize to their site-specific workflows and populations. }\end{array}$ \\
\hline \multicolumn{2}{|r|}{ Operating Amongst } \\
\hline $\begin{array}{l}\text { The } \\
\text { Resources }\end{array}$ & $\begin{array}{l}\text { Teams may benefit from both one-on-one, in-person time with consultants, facilitators as well as the full team membership for decision-making on action } \\
\text { plans and scorecards. This could occur in advance or follow province-wide in-person sessions. } \\
\text { Learning sessions may be modified for more virtual participation (with facilitators and consultants going to teams) to ensure efficient time management } \\
\text { and value. } \\
\text { Management and team support is consistently required to ensure team members (especially in smaller or rural teams) understand sufficient time is } \\
\text { available for RMoC-related activities separate from clinical responsibilities. } \\
\text { Ensure external, expert facilitators at Learning Sessions or related events have experience directly linked to the team's practice or population. }\end{array}$ \\
\hline The Patient & $\begin{array}{l}\text { Teams must be coached to sustain learnings related to a shared patient-first language (often built from RMoC learnings and HealthChange }{ }^{\circledR} \text { ). Tactics } \\
\text { include keeping such language learnings on team meeting agendas for discussion and possibly small incentive-based activities. }\end{array}$ \\
\hline The Team & $\begin{array}{l}\text { Management and leadership must consistently demonstrate collaborative support for RMoC implementation (i.e. not just at start, not sporadically). } \\
\text { Avoid top-down decision-making with teams, especially around the logistics of RMoC implementation to ensure local customization of provincial standards } \\
\text { where relevant and meaningful. Collaborate with teams on major decisions and timelines; empower teams to complete detail-related decisions. } \\
\text { Tailor team education and communication to that team's experience with quality improvement, research and systemic change. Novice teams will need } \\
\text { more in-depth education and long-term support, especially on evaluation and data collection. } \\
\text { Teach team members how to keep track of and communicate priorities in progress to navigate staff changes at management and team level. } \\
\text { Teach teams and provide standardized tools to support communication regarding implementation rationale and activities to colleagues (on team and at } \\
\text { facility) who are not part of implementation process but are (or will be) impacted by RMoC implementation process or outcomes. }\end{array}$ \\
\hline \multicolumn{2}{|r|}{ Integrating the RMoC } \\
\hline $\begin{array}{l}\text { The } \\
\text { Metrics }\end{array}$ & $\begin{array}{l}\text { Clarify the pros and cons of iPad use for data collection (e.g. for some seniors and homecare patients, iPads lead to lost privacy and fewer open-text } \\
\text { responses in the WatLX }{ }^{\mathrm{TM}} \text { ). } \\
\text { Permit flexibility in data collection (e.g. iPad or paper copies with team data entry). } \\
\text { Give earlier, more-frequent team access to mandatory metrics' data (at aggregate level) to facilitate practice changes, improvement of implementation } \\
\text { flaws, and team engagement. Training and messaging must clarify this access. } \\
\text { Support teams in better customization of approaching the non-mandatory metrics (especially safety metric) by either re-considering their value and } \\
\text { necessity; clarifying their necessity to teams more often; or making them optional (e.g. if no relevant safety metric, do two efficiency metrics). } \\
\text { Allow teams to implement the RMoC through a staged-gate approach to avoid teams implementing everything "falsely" and "going through the motions". }\end{array}$ \\
\hline $\begin{array}{l}\text { Available } \\
\text { Information }\end{array}$ & $\begin{array}{l}\text { Support and create opportunities for team leads to share RMoC-related information with other team members in a memorable, valuable and efficient way } \\
\text { (e.g. a regular, brief overview of summary statistics at team meetings). } \\
\text { Ensure that in-person learning (when providers must travel and lose clinical time) are directly applicable, memorable, useful and efficient (e.g. } \\
\left.\text { HealthChange }{ }^{\circledR}\right) \text {. } \\
\text { Provide operational details to save team time and frustration (e.g. early-adopter examples of logistical planning, clerical staff involvement). } \\
\text { Facilitate mentorship between early-adopter teams and new teams, ideally when there is commonality between patient populations, geography and service } \\
\text { options. }\end{array}$ \\
\hline $\begin{array}{l}\text { RMoC vs. } \\
\text { Program }\end{array}$ & $\begin{array}{l}\text { Clarify amongst leadership what takeaways from the RMoC are essential and what are nice to have. Confirm team messaging prioritizes essential RMoC } \\
\text { takeaways and how the RMoC is distinguishable from service options. } \\
\text { Highlight that uniqueness and commonality are not mutually exclusive. Clarify and initiate connections (and regular follow-up meetings) between teams } \\
\text { across service types, Zones and geographies to foster inter-team support and learning. } \\
\text { Support teams with efficient, appropriate advertising examples and strategies to enhance their referrals for novel programming. }\end{array}$ \\
\hline
\end{tabular}

\section{Contextualizing Findings within Broader Literature}

These findings corroborate many empirically-recognized facilitators and barriers to the implementation success of models of care. Facilitators-wise, we saw that individual acceptance, supportive leadership, distribution of decision-making roles, and the power of systematic measurement and sustainability were critical $[21,24,25,27]$. Barriers-wise, limited resources, lack of buy-in, communication, and overwhelmed or unsupported staff were present in Alberta as in other jurisdictions that struggled with model-of-care implementation [18, 20, 21, 24, 27]. We move beyond this extent literature in several ways.

First, previous research emphasized organizational structures that work to impede or facilitate model-of-care implementation [18, 20, 21, 24, 25, 27]. Our findings focus less on organizational or policy factors and rather emphasize the importance of the interpersonal factors, particularly emotional and communicative factors. In the language of the Consolidated Framework for Implementation Research (CFIR) [28], the intervention and individuals 
involved with the intervention were more determinative of the implementation experience, while the inner and outer settings as well as the process of implementation were influential but less prominent.

Individual connection to, and clarity about, the RMoC was important. The navigation of emotions was a conspicuous process in the implementation experience. Teams that struggled in implementation generally got "stuck" and could not steer the emotional fallout of large-scale change, novel transdisciplinary approaches, and dynamic team membership. Team motivation resulted from the emotional connection between the individual team members and the RMoC vision. Lack of connection meant lack of motivation, and successful RMoC implementation was distant. Teams could get behind neither increased data collection nor data-driven innovation. This was further compounded by teams noting that the standardized metrics lacked sensitivity in many rehabilitation populations, had ceiling effects, and likely suffered from strong acquiensence and social desirability bias.

The RMoC - the intervention itself - had adaptable and requisite components [28]. The adaptable components sometimes exaggerated confusion around RMoC vision and aims. In particular, Early Adopters could select the patient population and type of service programming upon which to apply the RMoC components. This selection was informed by local needs, interests and available resources. Where teams introduced novel service programming and were somewhat unsure about the RMoC, that insecurity exacerbated as the new program (e.g. a new group program for balance) and the RMoC (i.e. a patient-centred framework to promote shared decision-making, standardized quality of care, and data-driven innovation) became conflated. Meanwhile, the requisite components such as the collection of standardized metrics faced a great deal of resistance from many teams. These concerns targeted the nature and content of the measurement tools. In implementing models of care such as the RMoC, the challenges consequent to the adaptable and requisite interventional components must be made explicit so that they can be addressed.

Second, this study addresses the call to understand why models of care work in a particular jurisdiction and the factors that influence outcomes when transferring between jurisdictions $[13,14]$. Through the common challenges and the characteristics of confident teams, we see jurisdictional lynchpins. The size, dynamism, resources, and attitudes of all rehabilitation staff at a particular site informed the subset, Early-Adopter team success in realizing the RMoC facets and aims. Rural teams struggled more often with fewer resources, smaller teams, and thus less sustained reprieve from clinical duties to spend the time required to understand the RMoC and implement its component parts. Change in team membership was common across Alberta, but smaller teams often felt effects of longer gaps in coverage to fill the position and the learning curve of the new personnel.

Third, and finally, this study confirms the importance of sustainability considerations in model-of-care implementation. The training associated with the RMoC (along with HealthChange ${ }^{\circledR}$ ) likely offers gains in shared decision-making and functional goal-setting quality and frequency. These gains can be lost. Providers faced challenges to sustaining the gains in patient-centredness and shared decision-making. These include competing responsibilities, lack of clarity or connection to the RMoC vision, less traditional clinical settings such as group programming, and team dynamics. Teams adopting the new models of care must consider team- and patient- strategies for sustainability. For example, after training courses are complete, teams must plan the logistics of developing a community of practice that carries the conversation forward around the learnings.

\section{Limitations}

We recognize five major study limitations. First, pre-existing team dynamics carried into the focus group and may have affected candor and communication styles. While no managers participated in focus groups, clinical or team leads were present. Hierarchy was unavoidable. One focus group seemed less candid or members were mostly quiet outside of the team lead. We also noted that, while all teams were collegial and eventually got to consensus, one team had members who openly disagreed with each other at the start. For this team, it seemed to be their traditional communication style because there were no signs of discomfort, and consensus or mutual respect and understanding, were present at the end of each discussion point.

Second, not all focus groups occurred at the same time of the day or at the same time in the Innovation-Learning-Collaborative process. The latter may lead to different levels of recall or acceptance around the implementation experience. The former seemed influential as afternoon focus-group participants seemed quieter and less-forthcoming. Whether due to fatigue or post-prandial issues, we may not have fully captured the all participants' experience.

Third, due to feasibility and efficiency, the co-facilitator for the focus groups was not constant; had different levels of research training, experience and interest; varied in the level of detail in note-taking; and varied in focus-group involvement. Two focus groups involved the patient co-investigators as cofacilitators, which may have influenced the level of candor of the focus-group participants. We aimed to minimize this limitation by having the same moderator for each focus group, and trying to have debriefing conversations with all co-facilitators immediately after the focus group to ascertain cofacilitator perceptions while fresh.

Fourth, we collected both focus-group and interview data; there was greater variability of information shared by participants in these two data-collection modalities. Participants typically chose interviews for scheduling and convenience. Some interviews lacked the elaboration of focus groups. Ethically and feasibly, interview opportunities were necessary. Given there was little dissent and infrequent disagreement amongst focus group participants, it suggested general consensus. The interview-based results were similar to the focus group discussions; but of course, the interview-participants did not benefit from the discussion with colleagues.

Finally, we did not have access to full peer review of all interview and focus group transcripts for both studies. For the Early Adopter study, the researchtrainee co-facilitator gave feedback on the lead-researcher coding on three transcripts. Availability and costs prohibited more in-depth and independent second assessments on coding. Many other tactics were used to promote rigour including audit trail, thick description, and negative case analysis.

Page $11 / 17$ 


\section{Conclusion}

This study has organizational relevance to health-systems aiming to use models of care as frameworks that can advance patient-centred care in alliedhealth-dominant domains. We clarify the professional experience of Early Adopters of the RMoC, and found that experience centres on three major themes: the navigation of emotions, the operation amongst myriad dynamics, and the integration of model details. More importantly, this experience provides a foundational information resource to expose the seminal differences between jurisdictional success or failure in RMoC implementation. We offer future adopters information on common challenges to support preparedness, and strategies to overcome them. Possible future research directions include (a) rigorous development, testing and implementation of the training strategies identified, and (b) evaluating the RMoC itself using research designs that acknowledge and measure fidelity.

\section{List Of Abbreviations}

EQ-5D-5L: Standardized Quality of Life instrument developed by the EuroQol group

PaCER: Patient and Community Engagement Researcher

RMoC: $\quad$ Rehabilitation Model of Care

WatLX $^{\mathrm{TM}}$ : Outpatient Rehabilitative Care Patient Experience Survey

\section{Declarations}

\section{Ethics Declarations}

\section{Ethics Approval and consent to participate}

This study was approved by the Conjoint Health Research Ethics Board, University of Calgary (REB18-0967). All participants provided written informed consent prior to participation.

\section{Consent for publication}

Consent for publication was obtained from all participants in this study.

\section{Competing Interests}

The authors declare that they have no competing interests.

\section{Availability of Data and Materials}

The datasets generated and analyzed during the current study are not publicly available because the qualitative focus-group transcripts cannot be completely de-identified for public sharing, but can be made available in a highly-redacted form from the corresponding author upon reasonable request.

\section{Acknowledgements}

We acknowledge our participants from the Early Adopter teams as well as consultants and leadership at Alberta Health Services. We acknowledge the site managers and non-participating staff members at each site who were facilitated participant time away from clinical responsibilities to take part in this study. We thank our Patient and Community Engagement Researchers (PaCERs), Jean Miller and Sylvia Teare, for their advice, insight and support in the broader research program on shared decision-making in community rehabilitation. We particularly thank the provincial and regional leadership at Alberta Health Services, including Lisa Warner and Elaine Finseth, who were (and continue to be) champions of this work.

\section{Author Contributions}

KPM helped contribute to the study's conceptualization and design; implemented the study methodology, managed resources, and developed all manuscript drafts. KO helped contribute to the study's conceptualization and provided ongoing supervision in close collaboration with the other senior authors (SV,TW) regarding its methods, conduct, analysis, and manuscript development. KC helped contribute to the study's operationalization; provided ongoing support on conduct, analysis, and manuscript development; and, reviewed and edited this manuscript. JM helped contribute to the study protocol development; consulted on protocol methods; and reviewed and edited this manuscript. ST helped contribute to the study protocol development; consulted on protocol methods; and reviewed and edited this manuscript. SV helped contribute to the study's conceptualization and provided ongoing supervision in close collaboration with the other senior authors (KO, TW) regarding its methods, conduct, analysis, and manuscript development. TW helped contribute to the study's conceptualization and provided ongoing supervision in close collaboration with the other senior authors (KO, SV) regarding its methods, conduct, analysis, and manuscript development.

\section{Funding Support}


This work was supported by the Canadian Institutes for Health Research Health System Impact Fellowship [Code 201705HI7-388576-170744, 2017].

Supplemental funding was provided by the Strategic Clinical Networks ${ }^{\mathrm{TM}}$ and Research Challenge portfolios at Alberta Health Services.

\section{References}

[1] AHS Provincial Rehabilitation Forum. Rehabilitation Strategic Plan 2016-2019. 2016.

[2] Alberta Health Services - Health Professions Strategy \& Practice. Current State Analysis: Ambulatory Community Rehabilitation Services. Edmonton, AB, 2016.

[3] Strategy HP. Ambulatory Community Rehabilitation: A Review of the Literature. 2015.

[4] Alberta Health Services. Community Rehabilitation Model of Care - Guide for Year 1. Edmonton, AB, 2017.

[5] Alberta Health Services. the Patient First. Heal (San Fr, 15: 502-508.

[6] Hughes L. AHS Health Plan \&amp; Business Plan 2016-17http://www.albertahealthservices.ca/assets/about/publications/ahs-pub-healthbusiness-plan.pdf (2016).

[7] Coulter A. Making shared decision making a reality: no decision about me without me. Londong, 2011.

[8] Health D of. Liberating the NHS: No decision about me without me.

Londonhttps://www.gov.uk/government/uploads/system/uploads/attachment_data/file/216980/Liberating-the-NHS-No-decision-about-me-without-meGovernment-response.pdf (2010).

[9] Pope TM. Certified Patient Decision Aids: Solving Persistent Problems with Informed Consent Law. J Law Med Ethics 2017; 45: 12-40.

[10] Canada 's Strategy for Patient- Oriented Research ( SPOR ) The SPOR Rewarding Success Initiative.

[11] Alberta Innovates. The Alberta SPOR Support Unit.

[12] Advisory Panel on Healthcare Innovation. Unleashing Innovation: Excellent Healthcare for

Canadahttp://www.healthycanadians.gc.ca/publications/health-system-systeme-sante/report-healthcare-innovation-rapport-soins/alt/report-healthcareinnovation-rapport-soins-eng.pdf (2015).

[13] Kirk MA, Kelley C, Yankey N, et al. A systematic review of the use of the Consolidated Framework for Implementation Research. Implement Sci 2015; 11: 72.

[14] Birken SA, Powell BJ, Presseau J, et al. Combined use of the Consolidated Framework for Implementation Research (CFIR) and the Theoretical Domains Framework (TDF): A systematic review. Implement Sci 2017; 12: 1-14.

[15] Briggs AM, Chan M, Slater H. Models of Care for musculoskeletal health: Moving towards meaningful implementation and evaluation across conditions and care settings. Best Pract Res Clin Rheumatol 2016; 30: 359-374.

[16] Esmail L, Moore E, Rein A. Evaluating patient and stakeholder engagement in research: moving from theory to practice. Eff Res 2015; 4: $133-145$.

[17] Kadu MK, Stolee P. Facilitators and barriers of implementing the chronic care model in primary care: a systematic review. BMC Fam Pract 2015; 16: 12.

[18] Holm AL, Severinsson E. Perceptions of the need for improvements in healthcare after implementation of the Chronic Care Model. Nurs Health Sci 2014; 16: 442-8.

[19] Elias B, Barginere M, Berry PA, et al. Implementation of an electronic health records system within an interprofessional model of care. J Interprof Care 2015; 29 : 551-4.

[20] Van Mierlo LD, Meiland FJM, Van Hout HPJ, et al. Towards personalized integrated dementia care: a qualitative study into the implementation of different models of case management. BMC Geriatr 2014; 14: 84.

[21] Eghaneyan BH, Sanchez K, Mitschke DB. Implementation of a collaborative care model for the treatment of depression and anxiety in a community health center: results from a qualitative case study. J Multidiscip Healthc 2014; 7: 503-13.

[22] Speerin R, Slater H, Li L, et al. Moving from evidence to practice: Models of care for the prevention and management of musculoskeletal conditions. Best Pract Res Clin Rheumatol 2014; 28: 479-515. 
[23] Dziedzic KS, French S, Davis AM, et al. Implementation of musculoskeletal Models of Care in primary care settings: Theory, practice, evaluation and outcomes for musculoskeletal health in high-income economies. Best Pract Res Clin Rheumatol 2016; 30: 375-397.

[24] Novick G, Womack JA, Lewis J, et al. Perceptions of Barriers and Facilitators During Implementation of a Complex Model of Group Prenatal Care in Six Urban Sites. Res Nurs Heal 2015; 38: 462-474.

[25] Anna Starling. Some assembly required: implementing new models of care / The Health Foundation. Londonhttps://www.health.org.uk/publication/some-assembly-required (2017, accessed 28 June 2018).

[26] Briggs AM, Chan M, Slater H. Models of Care for musculoskeletal health: Moving towards meaningful implementation and evaluation across conditions and care settings. Best Pract Res Clin Rheumatol 2016; 30: 359-374.

[27] Kadu MK, Stolee P. Facilitators and barriers of implementing the chronic care model in primary care: a systematic review. BMC Fam Pract 2015; 16: 12.

[28] Damschroder LJ, Aron DC, Keith RE, et al. Fostering implementation of health services research findings into practice: a consolidated framework for advancing implementation science. Implement Sci 2009; 4: 50.

[29] Damschroder LJ, Aron DC, Keith RE, et al. Fostering implementation of health services research findings into practice: a consolidated framework for advancing implementation science. Implement Sci 2009; 4: 50.

[30] Van Reenen M, Janssen B. EQ-5D-5L User Guide. Basic Inf how to use EQ-5D-5L Instrum 2015; 28.

[31] McMurray J, Stolee P, McNeil H, et al. WatLX: Outpatient Rehabilitative Care Patient Experience Survey. Waterloo, 0 N, 2017.

[32] Alberta Health Quality Council. Alberta Quality Matrix for Health User Guide. Calgary, ABhttps://d10k7k7mywg42z.cloudfront.net/assets/569d416fa0b5dd02d80e6269/HQCA_User_Guide_Web.pdf (2005).

[33] Alberta Health Services. Alberta Health Services Strategic Clinical Networks: Guide to Establishing an Innovation Collaborative. Edmonton, AB, 2014.

[34] Institute for Healthcare Improvement. The Breakthrough Series: IHI's Collaborative Model for Achieving Breakthrough Improvement. Bostonhttp://www.ihi.org/resources/Pages/IHIWhitePapers/TheBreakthroughSeriesIHIsCollaborativeModelforAchievingBreakthroughImprovement.aspx (2003).

[35] Werle J, Dobbelsteyn L, Feasel AL, et al. Measuring factors affecting implementation of health innovations: a systematic review of structural, organizational, provider, patient, and innovation level measures. Health Policy (New York) 2012; 8: 32.

[36] Smith C, Christiansen T, Dick D, et al. Performance management tools motivate change at the frontlines. Healthc Manag Forum 2014; 27 : 15-19.

[37] Chaudoir SR, Dugan AG, Barr CH. Measuring factors affecting implementation of health innovations: a systematic review of structural, organizational, provider, patient, and innovation level measures. Implement Sci 2013; 8: 22.

[38] Carter P, Ozieranski P, McNicol S, et al. How collaborative are quality improvement collaboratives: a qualitative study in stroke care. Implement Sci 2014; 9: 32.

[39] Gale J, Skouteris H. Health coaching: Facilitating health behaviour change for chronic condition prevention and self-management. In: Caltabiano M, Ricciardelli L (eds) Handbook of Applied Topics in Health Psychology. Wiley-Blackwell, 2013.

[40] HealthChange Associates, Alberta Health Services. Person-Centred Practice Using HealthChange Methodology. Edmonton, AB, 2017.

[41] Manhas KP, Olson K, Churchill K, et al. Shared Decision-Making Experiences in Community Rehabilitation in Alberta, Canada. Under Review

[42] Manhas KP, Olson K, Churchill K, et al. Perceptions of Shared Decision-Making and Collaborative Goal-Setting after the Implementation of a Novel Rehabilitation Model of Care in Alberta, Canada. Under Review

[43] Speziale HJS, Carpenter DR. Qualitative Research in Nursing: Advancing the Humanistic Imperative. Lippincott. Philadelphia, PA, 2007.

[44] Spradley J. The Ethnographic Interview. Belmont, CA: Wadsworth, 1979.

[45] Cruz E, Higginbottom G. The use of focused ethnography in nursing research. Nurs Res 2013; 20: 36-43.

[46] Higginbottom G, Pillay JJ, Boadu NY. Guidance on Performing Focused Ethnographies with an Emphasis on Healthcare Research. Qual Rep 2013; 18: $1-6$. 
[47] Krueger RA, Casey MA (Mary AW. Focus groups: a practical guide for applied research.

SAGEhttps://books.google.ca/books/about/Focus_Groups.html?id=ySKeSZeWywMC\&redir_esc=y (2009, accessed 29 June 2018).

[48] Krueger RA, Casey MA (Mary AW. Focus groups: a practical guide for applied research.

[49] Milne J, Oberle K. Enhancing Rigor in Qualitative Description: Journal of Wound Ostomy \&amp; Continence Nursing. J Wound Ostomy Cont Nurs 2005; 32: 413-420.

[50] Sim J. Collecting and analysing qualitative data: issues raised by the focus group. J Adv Nurs 1998; 28: 345-52.

[51] Lambert SD, Loiselle CG. Combining individual interviews and focus groups to enhance data richness. J Adv Nurs 2008; 62: 228-37.

[52] Reed J, Payton VR. Focus groups: issues of analysis and interpretation. J Adv Nurs 1997; 26: 765-771.

[53] McClure NS, Sayah F Al, Xie F, et al. Instrument-Defined Estimates of the Minimally Important Difference for EQ-5D-5L Index Scores. Value Heal 2017; 20: 644-650.

\section{Figures}

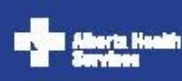 \\ REHABILTTATION MODEL OF CARE}

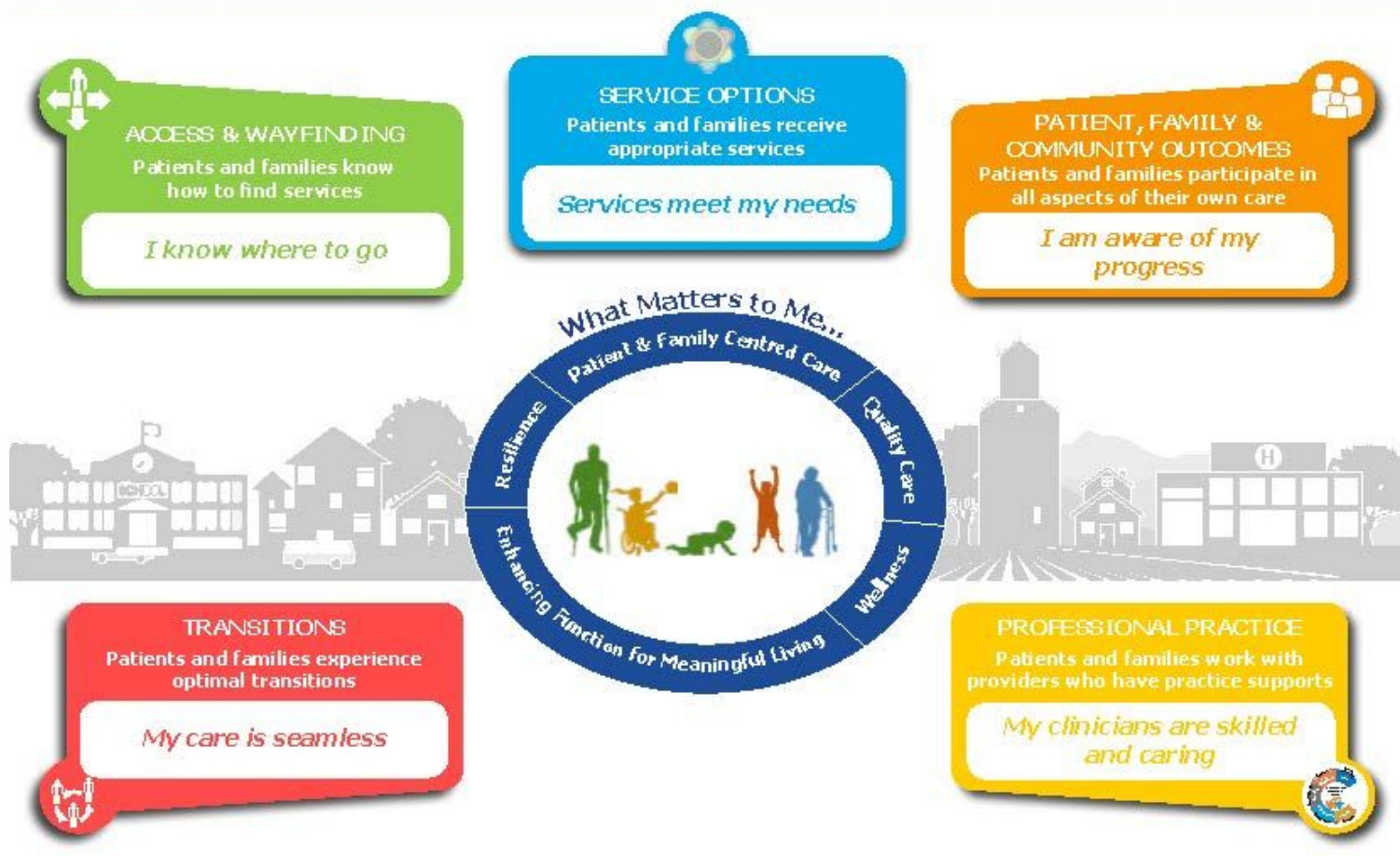

RESEAROH | INNONATION | TEOMOLOGY

\section{Figure 1}

Alberta Health Services Rehabilitation Model of Care 
Navigating Emotions

Shared Language

- Finding a Common Language

- Training

-Trans-disciplinary

Feelings

- Frustration

- Anxiety

- Overwhelmed

Approach to Failures

-When Candid

- Fail Fast, Fail Forward

- Fear of Changing Plan
Operating Amongst

The Patients

- Readiness

- Screening and intake

- Consent

\section{The Team}

- Management

- Team Changes

- Other Colleagues

The Resources

- Perceived Efficiency

- Costs of Learning Sessions

- Clinical Responsibilities
Integrating the Model

\section{Metrics}

- Difficult to See Value

- Some Metrics Problematic

- Access to Data

Model vs. Program

- Novelty

- One or Other

- Priority

Available Information

- Avoid Extraneous Info

- Team Lead Access

- In-Person Memorable

Figure 2

Early Adopter Professional Experiences During RMoC Implementation in Community Rehabilitation.

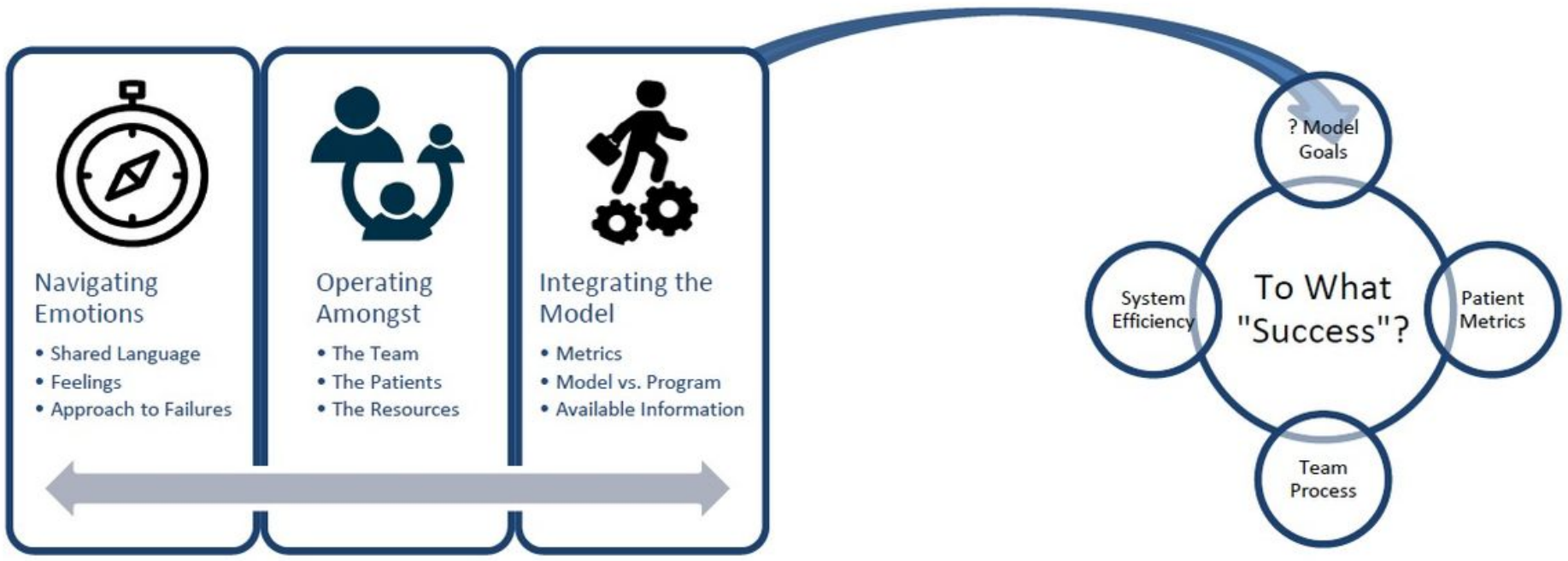

Figure 3

Early-Adopter Providers' Perceptions of Success as Multi-Faceted 

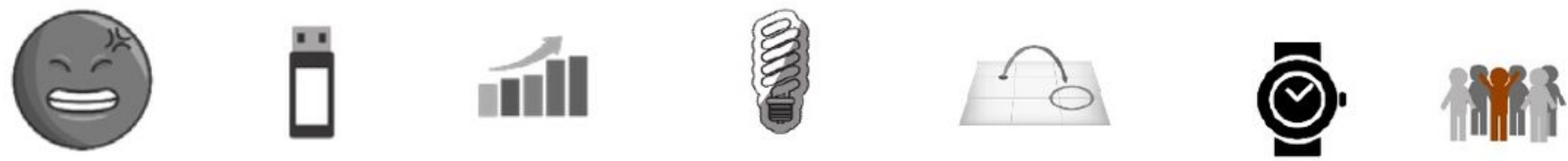

$\begin{array}{cccc}\text { Hard to } & \text { Lack of } & \text { Unclear on } & \text { Lack efficient } \\ \text { handle } & \text { timely } & \text { metric } & \text { updating + } \\ \text { initial } & \text { data } & \text { value }+ & \text { training }\end{array}$

emotions

access

relevance

strategies

\begin{abstract}
Unclear
on $\mathrm{RMoC}$

aim, key

parts
\end{abstract}

Lack time away

from clinical

responsibilities
Perceptions

of

uniqueness

impede

\title{
Figure 4
}

Common Challenges in the RMoC Early Adoption Process

\begin{tabular}{|cc|c|c|}
\hline & Common Traits of Confident Teams \\
$\begin{array}{c}\text { Coping Strategies } \\
\text { for Change }\end{array}$ & $\begin{array}{c}\text { Found Shared } \\
\text { Language }\end{array}$ & $\begin{array}{c}\text { Approach to } \\
\text { Failure }\end{array}$ & by Management
\end{tabular}

Figure 5

Figure 5. Common Features of Confident, Satisfied Early-Adopter Teams

\section{Supplementary Files}

This is a list of supplementary files associated with this preprint. Click to download.

- bmcimpICOREQchecklistManhasEAimpl083019.pdf 